\title{
The Shackles of Practice: History of Psychology, Research Assessment, and the Curriculum
}

\author{
Alan Collins and Geoff Bunn
}

\section{Introduction}

The history of psychology faces an uncertain future in Britain in the second decade of the twenty-first century. In some respects, its prospects appear healthy. Thanks to the mandatory inclusion of Conceptual and Historical Issues on the British Psychological Society accredited undergraduate psychology syllabus, for example, students studying in British universities now have an array of new history of psychology textbooks to choose from (Brysbaert \& Rastle, 2012; Jones \& Elcock, 2001; Richards, 2009; Smith, 2013; Tyson, Jones, \& Elcock, 2011). Over the same period, historians have produced an impressive array of theoretically informed works illustrating just how rich, nuanced, and informative the history of psychology is (e.g. Bunn, Lovie, \& Richards, 2001; Hall, Pilgrim, \& Turpin, 2015; Thomson, 2006). Much has been done to answer the excoriating criticisms of earlier scholarship (Rose, 1989; Young, 1966). Bolstered by theoretical ideas developed over the last 30 years and explored further in this issue, there are powerful arguments for psychologists to take history seriously.

In other respects, however, the area that explicitly links history and psychology, the history of psychology, is in distinct decline in Britain. Membership of the British Psychological Society's History and Philosophy of Psychology Section has remained consistently low during a period of rapid expansion of the discipline as a whole. Only a tiny handful of professional historians of psychology attend the Annual Section Conference, which had to be cancelled in 2015 because of a dearth of submissions. Within British academic psychology it is currently more marginal than ever. It is unclear whether it will retain any sort of presence as a research area. Its future within British psychology is precarious, and it is clear that there are threats elsewhere too (Krampen, 2016).

We argue that understanding the relations between history and psychology is not only a matter of developing ever richer accounts of the intellectual relations between the two areas, important though these are, but is also a matter of understanding the material conditions faced by those scholars for whom such conditions are increasingly problematic: historians of psychology. We are well aware that the term "material conditions" has echoes of Marxist analysis. We do not offer a Marxist account here though; for example, we do not examine relations of production, class relations, or labour process, and we do not concentrate on power. Nor do we adopt the sociological usage that typically refers to more local conditions such as laboratory practices and the like. However, we wish to persevere with the term as capturing something of the type of circumstance with which we are concerned. It also intended to capture the idea that history of psychology is itself an historical category pro- 
duced by social relations. We should also note that the history of psychology has as much of a claim to a place in the humanities as it does to one in departments of psychology. Indeed, this whole debate can be seen as part of the ongoing struggle to define the scope and nature of psychological science. For the current article, we are limiting our remarks to the place of history within psychology departments largely because of the strong arguments regarding history as being integral to psychology, some of which we recap before moving on to consider the impact of material conditions on the status of the area in the UK.

\section{A Theoretical Case}

In our view, there are cogent, compelling, and persuasive arguments for a history of psychology. One central set of contentions is around the nature of psychological concepts and psychological knowledge. Historians such as Kurt Danziger, Graham Richards, and Roger Smith have documented how the historical contingency of psychological categories renders them discursively unstable (Danziger, 1997; Hacking, 2007; Smith, 2005). Psychological language is burdened with meanings that echo earlier uses but also take on new ones within a particular social context (Richards, 1989). The apparent coherence of psychology's subject matter is held together by language (e.g. metaphor and rhetoric; Leary, 1994) but also by practical techniques (e.g. operationism; Green, 1992; Rogers, 1989). The discursive flexibility of psychological categories means they can be applied (in business, educational, and health contexts) but also that they can become vehicles for the production and maintenance of specific visions for the social order. Historians such as Ellen Herman and Nikolas Rose have examined how practices fundamentally shaped by psychology have become integral to producing and governing categories of persons under conditions of solid and liquid modernity (Bauman, 2000; Herman, 1995; Rose, 1985, 1989). These practices emerge from particular social, cultural, and political circumstances and make possible different forms of subjectivity, personhood, and "modal selves" (Susman, 1984). Historical conditions shape them but they also help to produce conditions of possibility for the emergence of new identities. Psychology contributes to changing who we are, how we are acted upon, and how we act upon ourselves.

Historical work has demonstrated that rather than discovering eternal truths, psychology is frequently, if not always, engaged in a project of investigating regularities that are products of particular historical circumstances (Gergen, 1973). Such histories need not close off the possibility that there may be universal, external referents that constrain our language and practice (though most critical historians are sceptical of such claims), but they do draw attention to how psychological concepts and practices have a fundamentally historical dimension. They also highlight the important connections between psychology and the objects of psychological study. As Roger Smith has put it: "When we develop our knowledge of human beings, we do not just change knowledge but potentially what it is to be human. It follows that psychology is not only the study of human thinking, feeling, acting, and interacting: it has itself — like any other human science — brought into being new ways of thinking, feeling, acting, and interacting" (Smith, 2005, p. 56; also Richards, 1987, 2002). As Nikolas Rose has claimed, humans are themselves historical and cultural artefacts (Rose, 1996, p. 22). ${ }^{1}$ Such claims, we believe, render history an inescapable part of psychology. 
These arguments for the fundamentally historical nature of psychology share intellectual roots and resonances with other historical and philosophical projects, be they Wittgenstein's philosophy of language (Wittgenstein, 1953), Foucault's “archaeology" of knowledge and technologies of the self (Foucault, 1973, 1977, 1988), or Collingwood's emphasis on the historical imagination in recapturing past patterns of thought (Collingwood, 1946). Scholars have also made links with sociological work on science ranging from the Edinburgh "strong programme" in the sociology of knowledge (Barnes, 1977; Bloor, 1976) to Actor Network Theory (Callon, Rip, \& Law, 1986; Latour, 2005; Law \& Hassard, 1999). Going back further, these histories of psychology also share with history of science a concern to shift away from excessive and unreflective celebration, presentism, and internalism.

Perhaps the most radical claim is that much of psychology's subject matter is unlike that of the natural sciences. Historians and philosophers have argued that there are fundamental differences between indifferent kinds (electricity, gravity, neurons, sodium chloride, and so on) and interactive kinds (personality, intelligence, neurosis, the taste of salt, and so on; the interactive-indifferent division is used by Hacking (1999) as a development of the more familiar natural versus human kinds differentiation). "Whereas in orthodox sciences there is always some external object of enquiry-rocks, electrons, DNA, stars - existing as essentially unchanging in the non-human world", writes Graham Richards, "this is not so for Psychology" (Richards, 2002, p. 7).

\footnotetext{
${ }^{1}$ These arguments are well rehearsed in cultural and historical psychology but have made few inroads into Psychology Departments in the UK.
} 
It would seem that psychology has for much of its history assumed that it is in the business of discovering and examining indifferent kinds when it is more appropriate to describe it as contributing to the construction of interactive kinds. ${ }^{2}$

It is difficult to imagine that there are psychological categories awaiting discovery, like gold nuggets embedded in rock strata. Nevertheless, the implied model of discovery still structures the tacit knowledge of many psychologists. Psychological research teams do not host press conferences to announce the discovery of hitherto unknown psychological entities, in contrast to the state of affairs in astrophysics, for example, when the discovery of gravitational waves was announced to the world's press in February 2016. Psychology's track record of producing laws is also modest. Even apparently renowned laws such as the Yerkes-Dodson law or the law of effect have been challenged or faced obsolescence through qualification (Roediger, 2008; Teigen, 1994, 2002). Facts too are presented differently in psychology, compared to how they are in the natural sciences, always allowing scope for qualification and the possibility of disagreement (Smyth, 2001). Morawski (1996) has argued that in grappling with the desire to construct a universal model of human subjectivity, early American psychology textbooks attempted to harmonise psychological with culturally prescribed modes of subjectivity. "I don't think psychology can ever dissociate itself from a certain normative program", Foucault said in a 1965 interview: "Every psychology is a pedagogy, all decipherment is a therapeutics: you cannot know without transforming" (Foucault, 1998, p. 255).

On this view it is more accurate to conceptualise psychological categories as emerging into discourse and becoming psychologised (Danziger, 1997; Goodey, 2011), rather than being "discovered". The meanings of interactive kind terms are always changing across time and place. Terms such as "race", homosexual, ADHD, hysteria, nervous breakdown, and emotion all have a history and can be understood as interactive kinds (Arnaud, 2015; Barrett, 2006; Shorter, 2013; Somerville, 2000; Timimi, 2005). In addition, psychological categories are not refuted as such; they merely go out of fashion. Psychology abandons its categories when they are no longer socially useful or meaningful in the culture. Character, feebleminded, and hormic spring to mind (although character seems to be experiencing a revival, e.g. Furnham \& Lester, 2012; Niemiec, 2013). Challenges have been mounted against the conceptual coherence of key psychological concepts such as attention (Anderson, 2011), schizophrenia (Geekie \& Read, 2009; Lasalvia, Penta, Sartorius, \& Henderson, 2015), the storage metaphor of memory (Brockmeier 2010; Randall, 2007), and "race" (Tate \& Audette, 2001). ${ }^{3}$ Some concepts, such as "race", have been sustained by powerful interests and not scientific findings or evidence-based

\footnotetext{
${ }^{2}$ Not all who are sympathetic to history of psychology believe this distinction to be essential or ultimately defensible. Smith (2007), for example, argues that in principle at least, all knowledge interacts with its objects (pp. 93-121; see also Khalidi, 2010; Tsou, 2007). There is insufficient room here to explore these differences in detail.

${ }^{3}$ Psychology's largely abandoned categories include accedie (with occasional revivals, e.g. in relation to burnout in academics, Bartlett, 1994), apperception, chagrin, clairsentience, conation, drapetomania, drive, habit, hysteria, instinct, limerence, moron, motivation, neurasthenia, psychon, race, sympathy, the will, and volition.
} 
arguments (Sussman, 2014). The term's flexibility and biological ambiguity have enabled it to be co-opted into a variety of political projects. "Race" is a racist term.

It matters profoundly which word one chooses to describe any human experience, psychological state, or form of identity precisely because language contributes to the phenomenology of personhood. Having a passion is not the same kind of thing as having an emotion; the joy one experiences on passing an exam is not the same as the joy at having given birth; melancholy is not the same as depression. Thus, terms like fantasy can, in some periods, be treated as fundamental psychological categories, while in other periods they are either ignored or made technical and stripped of much of their former meaning (Cornejo, 2015; Dixon, 2003). Psychologists can become "servants of power" (Baritz, 1960) precisely because psychology's constructs are sufficiently malleable to allow the many forms of power to function. Governmentality requires flexibility (Dean, 1999).

Unlike indifferent kinds which can exist outside of human culture and society, interactive kinds are made possible by a network of related discursive terms - a network that is a product of a particular human society and culture. All scientific objects from adenosine triphosphate to a high-pressure weather system are made possible by the epistemological networks they are embedded in (Daston, 2000). However, our understanding of gold's electrical conductivity is meaningful only as a result of our prior knowledge of the laws of electricity. In this epistemological sense, our knowledge of gold is "discursive". But nuggets buried in the rock pre-existed human culture and society and awaited discovery. Gold is (literally) a malleable metal, capable of being melted and poured into a mould or beaten into thin sheets. By contrast, human categories of selfhood are (metaphorically) only malleable in the significant and different sense of coming into existence necessarily and sufficiently within human society. Indifferent kinds predate the evolution of human consciousness, whereas interactive kinds are made possible by language and culture. Wealth is a discursive construct whose meaning is as function of particular social arrangements and networks of power. Human beings interact with wealth in a totally different way compared to how they interact with gold (Brinkmann, 2005, p. 773).

\section{Creating a Market in UK Higher Education}

There are, then, powerful arguments regarding history as an intrinsic part of psychology. Nevertheless, as we noted at the beginning of our article, we have serious concerns over the viability of the relationship in the current British university climate. Our worries arise from the conditions pertaining across the higher education sector. Over 20 years ago, Kurt Danziger reminded scholars that "tolerance for historical studies [of psychology] diminishes sharply as we enter the serious business of the discipline" (Danziger, 1994, p. 467). As Danziger implies, as soon as one enters the world of practice and decisions, such as who one should appoint to an academic post, well-intentioned beliefs in the value of history can quickly be sidelined. What was true in the 1990 s is even more so in the early twenty-first century. 
To put it bluntly, the powerful intellectual arguments for history of psychology, to which we have alluded above, have not advanced the situation of history within the discipline of psychology. In our view, the success of the intellectual case has been undermined by practical and political constraints that have emerged in the last 20 years. One particularly profound constraint stands out: the marketisation of the UK Higher Education sector in the context of the wider ideology of neoliberalism. It is to this wider context we now turn.

Higher education has traditionally been publicly financed in the UK with minimal or no tuition fees. Because the available number of university places was limited, performance in national standardised exams ("A" levels) was the mechanism that allowed universities to select applicants. Until 1998, universities were still essentially publicly funded, and students' tuition fees came from the public purse; limited fees were introduced from 2006 onwards. In 2009, the "Browne Review" or the Independent Review of Higher Education Funding and Student Finance was launched to consider the future direction of higher education funding in England. Initially commissioned by a Labour government, the committee published its findings in October 2010, 6 months after the Conservative-Liberal Democratic coalition government came to power. ${ }^{4}$ Chaired by Lord Browne of Madingley, the review recommended wide-ranging changes to the system of university funding in England, including removing the cap on the level of fees and increasing the income level at which graduates must begin to pay back their loans. The Education Act of 2011 ratified the proposal to increase the cap on annual tuition fees from $£ 3290$ to the maximum of $£ 9000$, the rate that the majority of universities immediately started charging. Paradoxically, the proportion of young people going to university has jumped from approximately $15 \%$ in the mid 1970 s, when a student's tuition fees were paid in full by government, to approximately $46 \%$ in 2013 , when fees were $£ 9000$ per annum. ${ }^{5}$

There have been further efforts to extend the market into higher education, such as enabling private providers to compete in the market (Brown \& Carasso, 2013). The attempt to create a market in higher education has resulted in the replacement of traditional ideals of intellectual autonomy, freedom, and financial security with demands for brand creation, competitiveness, and precarious employment. Managerialism is changing the nature, scope, and ambition of academic work (Hyde, Clarke, \& Drennan, 2012). Traditional assumptions about the professional role of academics are being challenged as both teaching and research practices are subjected to regimes of monitoring, assessment, and evaluation in terms of productivity and efficiency. The result is that academics must now spend considerable time

\footnotetext{
${ }^{4}$ Securing a sustainable future for higher education: an independent review of higher education funding and student finance. https:/www.gov.uk/government/publications/the-browne-reporthigher-education-funding-and-student-finance. Accessed 16 April 2016.

${ }^{5}$ See Times Higher Education, 23 July 2013, https://www.timeshighereducation.com/features/ participation-rates-now-we-are-50/2005873.article, and UK Government statistics at https://www. gov.uk/government/uploads/system/uploads/attachment_data/file/458034/HEIPR_ PUBLICATION_2013-14.pdf, both accessed 26 May 2016.
} 
both accounting for their activities in a form that managers can utilise, as well as engaging in those activities that managers deem legitimate in the first place. The true use value of scholarly labour is in decline, while the exchange value of produced commodities, as measured by an array of metrics, is on the rise.

As Lorenz (2012, p. 625) has concluded, managerialist discourse "is Orwellian in nature because it redefines concepts such as quality, accountability, transparency, and professionalism and perverts them into their opposites". Orwellian or not, it is hardly surprising that the academy's traditional values are being undermined. English universities are being repurposed as "engines of growth", reshaped as centres of applied expertise and repositioned as subordinate to society's "economic strategy" (Collini, 2012). The value of research, it is argued, must be measured in terms of its contribution to economic innovation. Teaching must be refocused to equip students with the vocational skills employers demand. The roles and expectations of academics and students alike are being refashioned: academics become service providers as students become consumers (Molesworth, 2010; Williams, 2012).

\section{The Assessment of Research}

While higher education has arguably always been in transition, the tectonic political movements of globalisation and neoliberalism have led to the introduction of managerialist ideology, which operationalises all activities as calculable, governable, and transportable (Giroux, 2014). Implicitly or explicitly, scholars have always been concerned with the issue of the quality of their work. What is comparatively new, certainly in terms of scale, is national governments initiating a process for assessing its quality. In the UK, this process has now been through six cycles, having started in 1986. The practice of performance-based research funding has now spread to (at least) another 14 countries (Bence \& Oppenheim, 2005; Hicks, 2012). Characterised as state regulation of the research market, such exercises have determined the amount of research-related income universities receive from central government (Palfreyman \& Tapper, 2014). The outcomes of research assessment exercises are expressed in various ways, but one particularly influential has been the production of national league tables for different subject areas, which are in turn used as markers of prestige. The results are held to have had effects on such things as the ability of institutions to attract the best qualified undergraduates, the most promising graduate students, and the most eminent staff (Owens, 2013). In sum, research assessments have become integral to the universities' management of income and reputation.

The Research Excellence Framework (REF), as it is currently called in the UK, remains controversial. Supporters point to positives such as accountability, higher research quality, increased productivity and value for money, and personal incentives to produce research of international repute. For example, the Higher Education Funding Council reported that the proportion of UK research judged to be "world leading" went from 14 to $22 \%$ between the 2008 and 2014 assessments. In contrast, critics point to the frailties of assessment methods, the lack of consensus on how to 
assess quality, and the shaping of considerations of research direction by the REF and associated metrics rather than the research question itself (Berche, Holovatch, Kenna, \& Mryglod, 2015; Hug, Ochsner, \& Daniel, 2014). Academic staff have also claimed that such exercises have distorted academic life, have been divisive, and have disadvantaged some (Harley, 2002; University and College Union, 2013).

Understanding how the UK research assessment exercises have contributed to the marginalisation of history of psychology within psychology requires a little more explanation of how they have operated (we concentrate on the most recent exercise but note that the effects have been cumulative). For the $2014 \mathrm{REF}$, universities submitted the work of their researchers to experts who had been chosen by the academic community. These assessors were organised into panels and then into subpanels or units of assessment. The work of a particular academic was sent to the unit of assessment (UoA) that was judged to be the most appropriate by the institution. For psychology, the relevant UoA was entitled "Psychology, Psychiatry and Neuroscience". ("History" had a UoA of its own. And it was possible for psychologists to have their work submitted to other panels, and some did so.) Generally, submissions from university departments consisted of four publications from each researcher entered, a description of the research environment relating to the department, and case studies showing how research conducted within the department had had social and/or economic impact. Not all academic staff had to be submitted into the assessment: universities made strategic decisions about which staff to submit. ${ }^{6}$

Submissions were graded by at least two members of each subpanel on the following areas: excellence of the publications, the research environment, and the impact of research. For each department, each of these three areas was awarded a grade of $1^{*}, 2^{*}, 3^{*}$, or $4^{*}$ (with a possible "unclassified" category) where $3^{*}$ corresponded to research demonstrating "Quality that is internationally excellent in terms of originality, significance, and rigour, but which falls short of the highest standards of excellence" and $4 *$ corresponded to "Quality that is world-leading in terms of originality, significance, and rigour". Only publications awarded the two highest grades, $3^{*}$ and $4 *$, fed into subsequent calculations about financial disbursement. However, all the ratings of submitted publications fed into a final aggregate score, akin to a grade point average, for each department. While the intention was that publications would be assessed by people with expertise in the field, in marginal or underrepresented areas, there was a risk of this not happening.

The economist Frederic Lee and his colleagues have argued over a number of years that one effect of research assessments on his discipline in British universities has been to reduce variety, producing what they describe as a homogenisation of economic research. They attribute this to recursive relations between the assessment exercise, the economics panel, journal rankings, and decision-making within economics departments (Lee, 2007; Lee, Pham, \& Gu, 2013). Lee et al. argue that entire areas of economics are effectively being marginalised and ignored. Recent work by Gunther Krampen supports a case for the history of psychology becoming similarly less prominent (Krampen, 2016). Using the PsycINFO database,

\footnotetext{
${ }^{6}$ Nor did research-active academic staff have to submit to the REF panel associated with their home academic department. Some academics submitted their work through an adjunct department.
} 
Krampen's analysis indicates that the frequency of publications in the history of psychology has steadily declined (as a proportion of psychology publications) from the mid-1980s (1.09\%) to the last 5 years $(2010-2014,0.4 \%)$. Repeating Krampen's analysis but for UK-only publication would, we believe, reveal an even gloomier picture. This has led to a general unease that research assessment might stifle some research, lead to risk-averse research directions, and elevate anticipation of what will be rewarded in the assessment above doing the best research (Owens, 2013).

In 2015, the Social Psychology Section of the British Psychological Society (BPS) commissioned a survey of its members' experience of REF 2014. The survey found that social psychologists doing quantitative research were more likely to be submitted to REF than those doing qualitative research, that institutions were greatly swayed by the impact factors of journals when considering what work to submit, and that institutions were generally risk averse when considering submission of social psychological research based on qualitative or mixed methods. The survey concluded that the result of REF was "a narrow and methodologically impoverished representation of UK social psychology". Margaret Wetherell, formerly Professor of Social Psychology at Loughborough and the Open Universities, characterised the situation for social psychology as one of "uncertain location, likely hardship, and a potential loss of institutional clout" (Wetherell, 2011, p. 402). Social psychology, especially discursive social psychology, has a great deal in common with history, especially if the theoretical claims with which we began hold true. The implication is clear: if social psychology is under threat, then the situation is worse for history of psychology. But rather than being a threat limited to narrowing of the subject or to invoking a particular methodological imperative, the threat is to the very existence of history of psychology within psychology.

In the most recent REF, the quality of publications accounted for $65 \%$ of the final "mark" with the remaining 35\% calculated from "impact" (20\%) and "research environment" (15\%). Impact was defined as research having "an effect on, change or benefit to the economy, society, culture, public policy or services, health, the environment or quality of life, beyond academia". Its inclusion in the REF was prompted by a culture and rhetoric of accountability that has a much longer history (see, for example, Rose \& Rose, 1970). It is clear, and has been clear for many years, that history of psychology struggles to demonstrate the effects of its research in a manner that might plausibly resemble the claims for impact in other areas of psychology. This is consistent with a larger concern that research in the humanities, arts, and, in places, the social sciences has to contend with narrowly defined impact agendas that are better suited to the natural sciences (Benneworth \& Jongbloed, 2010).

Then, of course, there is money. While research income was not an independent measure in REF, at research-led UK universities, the ability to attract research funds is frequently linked to prestige and personal promotion. It is not uncommon for departments to have targets for average research income per full-time academic. While no one is suggesting that the research income from history of psychology could sensibly be compared to that commanded by neuroscience, in the landscape of funded psychological research, history is again at the margins. Once more it 
becomes a matter of burden: the lack of research income from history simply makes the demands on other staff even greater.

The effects of research assessments permeate the academic landscape through to the language used in journals. In a lexicographic analysis of journal abstracts on PubMed between 1974 and 2014, Vinkers, Tijdink, and Otte (2015) counted the use of positive and negative words such as "novel", "robust", "innovative", and "disappointing". They found a proportionate increase in both but a much more marked increase in positive words from $2 \%$ of all words to $17.5 \%$ of all words, a within class increase of $880 \%$. In order to get published, researchers are increasingly using words that emphasise the status of their work. ${ }^{7}$ Presenting research as "groundbreaking" may contribute to it being regarded as such. While this might be dismissed as a trivial effect on journal rhetoric, we believe that dismissal would be a mistake: everything we subscribe to as historians and psychologists emphasises the importance of language and rhetoric (Bazerman, 1988; Billig, 1989, 1990; Richards, 1989).

A further indicator of the pressures of research assessment is the almost complete absence of young academic psychologists in Britain who claim history of psychology as a research interest, let alone as their main specialism. We are aware that this has been said before and there was rarely a time when there were large numbers of psychologists with history as their research specialism. The familiar claims that history does not belong within a science (with the possible exception of economics) and should therefore be excluded from the curriculum have been voiced for decades, informally and in print. But the pressures of the REF have given these claims renewed traction: what was once regarded as a rather quaint but harmless choice of (secondary) research topic is now more likely to be seen as a burdensome luxury that neither an individual nor a department can afford. Needless to say, we emphatically reject this view. However, eligibility for the REF is now effectively a prerequisite for most appointments in a British research-led university and internal promotion also frequently relies on a person's "REFability" (although government proposals to provide alternative promotion paths based on teaching are currently circulating). In such circumstances, and irrespective of philosophical defences of the historian's position, it becomes difficult to recommend the history of psychology as a research field for any graduate student embarking on an academic career. ${ }^{8}$

\footnotetext{
${ }^{7}$ PubMed is the search engine for the major medical database Medline. The lexicographic approach using corpus linguistics holds considerable promise within history of science and psychology (see, e.g. Pumfrey, Rayson, \& Mariani, 2012; Green, Feinerer, \& Burman, 2013).

${ }^{8}$ One obvious response to marginalisation in both research assessments and curriculum design would be to suggest, along with many of its critics, that historians of psychology should move camp and become members of history departments: history for historians and science for scientists. While history of science is itself a small specialism compared to, say, social and economic history, such a move has the obvious appeal that history of psychology is better aligned with the assessment criteria in history. It would also resolve the related tensions around the appropriateness of the kind of knowledge and knowledge production. While we see this as a possibility for some individuals, it risks undermining the hope of many historians of psychology that history is read by psychologists (Danziger, 1994). It also risks the status of historians within psychology: there is nothing "mere" about institutional structures and divides.
} 
When located within the larger discipline of psychology, the history of psychology fails to deliver on almost all of the criteria considered important. In the increasingly calculated world of universities, it generates little research income, journal impact factors and citation rates are typically low, published material often tests psychologists' understanding of what constitutes psychological knowledge, cases linking research to impact are rare and difficult to articulate, few students are attracted into research in the area, and many research articles (including several of our own) fail to contribute histories that substantiate the history-psychology mutuality. The material conditions of research assessment are dismantling the history of psychology's institutional base in psychology. These conditions are not divorced from values: they are a product of the notions of market that suffuse neoliberal agendas.

\section{The Crisis in Teaching Conceptual and Historical Issues}

Giroux (2002) has argued that neoliberalism substitutes the language of commercialisation, privatisation, and deregulation for civic discourse. Within the language and images of corporate culture that are now coming to dominate university life, citizenship itself is constructed as a privatised affair in which self-interested individuals compete for resources. It follows that certain areas of psychology will thrive under this regime while others will fail. Some fields of psychological practice and investigation have certainly come to prominence in recent years - and not solely as a result of their empirical achievements. We are thinking here of coaching psychology, for example, or positive psychology, two previously marginal specialisms that are now thriving, thanks to their valorisation of personal achievement and the pursuit of happiness through individual transformation based on self-work (Binkley, 2011a, 2011b; Christopher \& Hickinbottom, 2008). Other fields of psychology are also in the ascendant, nurtured by the liquid ontologies that neoliberalism demands, as Parker (2014) has argued. But one area in particular has triumphed above all others: cognitive neuroscience. We are persuaded that the success of the neuro-discourses in psychology has not been brought about solely by their empirical achievements but rather by a social and political context that renders their contributions evidently essential to contemporary conceptions of selfhood (Brenninkmeijer, 2010; Martin, 2010; Vidal, 2009). We live in an age of what has been called "the synaptic self" (LeDoux, 2002) or the "neurochemical self" (Rose, 2003). It seems that our discipline has either become overtaken by a neuromania (Legrenzi \& Umilta, 2011; Tallis, 2011), or perhaps it has been brainwashed (Satel \& Lilienfeld, 2013). As the neuro-disciplines continue their rise, the history of psychology falters. Ironically it is patient and principled historical and conceptual work that has done much to challenge these developments, though its impact on mainstream practices is sometimes difficult to discern (Moncrieff, 2006; Noë, 2009; Rose \& Abi-Rachid, 2013). 
Debates about the place of history of psychology in the psychology curriculum have been much rehearsed, and there have been concerns that history is often positioned as having only a pedagogical role (Danziger, 1994). The complaints are familiar: the reluctance of many academic psychologists to teach it, the resistance to it from many students (before they have actually studied it), the doubts over why any science should include its history as a compulsory part of the curriculum, the scepticism that it requires true expertise, and its awkward relation with research-led teaching are just some. Equally, however, there are counterarguments to each of these. The relationship between history and psychology is different from similar relations in other sciences. A significant number of academics have always enjoyed teaching it and many students are regularly enthralled by it. With the growth of big data and means of interrogating it, there are also new opportunities not just for research in history of psychology but also in teaching it (Green et al., 2013; Green \& Feinerer, 2015).

\section{Opportunities and the Teaching of History of Psychology}

It is in the area of undergraduate teaching that we believe there are some reasons for optimism. Since 2001, the British Psychological Society (BPS) has defined historical and conceptual issues as a "core area" for the undergraduate curriculum. The majority of undergraduate psychology courses in the UK are accredited by the BPS, and so most departments have developed their curricula with the BPS requirements in mind. ${ }^{9}$ The undergraduate psychology syllabus in Britain is also shaped by the Quality Assurance Agency for Higher Education (QAA), the independent body entrusted with monitoring, and advising on, standards and quality in UK higher education. ${ }^{10}$ The sections of the subject benchmark statement pertinent to conceptual and historical issues in psychology (CHIP) fall under the headings "Nature and extent of psychology" (3.7) and "Subject Knowledge and Understanding" (4.6) and state:

3.7 To summarise, psychology is a discipline concerning experience and behaviour that is of immense range and depth. It has evolved its own methodologies from those found in cognate areas. A degree in psychology implies an understanding of historical and contemporary psychological research alongside an appreciation of current and previous theoretical efforts to integrate and interpret empirical findings. To achieve this requires students to gain critical thinking skills developed within a context of rigorous empirical methodology. (QAA, 2010, p. 3)

4.6 The core knowledge domains within psychology include research methods, biological psychology, cognitive psychology, individual differences, developmental psychology and social psychology, although students will be exposed to other areas as well. In addition to

\footnotetext{
${ }^{9}$ One major reason for this is that a BPS-accredited first degree is usually required for further training in professions such as clinical and educational psychology.

${ }^{10} \mathrm{http} / /$ www.qaa.ac.uk/en/Publications/Documents/Subject-benchmark-statement-Psychology. pdf accessed 7 January 2016.
} 
these core areas, it is expected that students will gain knowledge of conceptual and historical perspectives in psychology. (QAA, 2010, p. 4)

The benchmark standards insist on the teaching of conceptual and historical issues on undergraduate psychology degrees. Furthermore, historical and conceptual issues clearly play a significant role in all of the typical attainment standards. On graduating with an honours degree in psychology, students should typically be able to: "understand the scientific underpinnings of psychology as a discipline, its historical origins, development and limitations" (QAA, 2010, Sect. 7.4, p. 4).

Because it defines conceptual and historical issues as a "core domain" of psychology, the British Psychological Society's own syllabus guidelines place more emphasis than the QAA on its importance in the undergraduate curriculum. ${ }^{11}$ All the core domains must be assessed, although they need not be delivered via a dedicated course unit or module. ${ }^{12}$

The indicative content for the area has a broader scope that most scholars in the field would embrace:

the study of psychology as a science; the social and cultural construction of psychology; conceptual and historical paradigms and models - comparisons and critiques; political and ethical issues in psychology; integration across multiple perspectives. (BPS, 2015, p. 18)

All of this should be welcomed. After all, both the BPS and QAA make history a recognised component of a regulated curriculum for undergraduate psychology. They endorse the metaphor we often use ourselves when trying to capture what psychology should be: the metaphor of "breadth". This is also at least consistent with another metaphor we use to justify history: that it provides perspective. However, while we see the stipulations of the BPS and QAA as opportunities, to others they are constraints that are sometimes resented. By making history a requirement, older, familiar oppositions have been renewed: staff who do not want to teach it yet are required to do so, many students dislike being compelled to study it, and many cannot see the justification for it being a compulsory part of the curriculum. The result has been anger from some about why it should be compulsory and concern from others about who and how they are going to teach it. It is doubtful that these stipulations have improved the situation of history of psychology. Nevertheless, for us as historians of psychology, they do provide some reason to retain a foothold in the discipline.

\footnotetext{
${ }^{11}$ The BPS "core domains" are biological psychology, cognitive psychology, developmental psychology, individual differences, social psychology, conceptual and historical issues in psychology, research methods, and empirical project. http:/www.bps.org.uk/system/files/Public\%20files/ $\mathrm{PaCT} /$ undergraduate_accreditation_2015_web.pdf accessed 6 January 2016. Of all the core domains however, only conceptual and historical issues need not have an associated practical element (qualitative or quantitative). We recommend that this oversight be corrected in subsequent editions of the Standards for the Accreditation of Undergraduate, Conversion and Integrated Masters Programmes in Psychology.

${ }^{12}$ Accreditation through Partnership 2015/16 Self-evaluation questionnaire for new undergraduate, conversion and integrated Masters programmes (UK) http://www.bps.org.uk/careers-education-training/accredited-courses-training-programmes/useful-accreditation-documents/ undergraduate-and-conversion-pr accessed 6 January 2016.
} 


\section{Conclusion}

We have argued that the material conditions produced by research assessments and curriculum changes have so marginalised history of psychology that its future in British psychology departments might appear a bleak one. One objection to our analysis is clear: that we are considering symptoms rather than causes. Goertzen (2008) argues that we must address causes. For him, the fragmentation and crises in psychology will only be resolved once there is more fundamental debate addressing the substance of psychology's philosophical tensions (Goertzen, 2008). On such a view, history's marginalisation, its place as a tiny fragment of a fragmented discipline, will not be corrected unless deeper issues of psychology's ontology and epistemology are addressed and solved. Once they are, the implication goes, everything will be better. We fully accept that philosophical issues often lie at the root of issues of marginalisation and, equally, we believe there are fundamental values at stake (Smith, 2007). For example, there is no doubt that the marginalisation of some areas of social psychology to which we have alluded is attributable to deep epistemological divides. We are also aware of the deeply politicised nature of decisions around exercises such as the REF. However, as vast swathes of social science and history have shown, marginalisation of groups is rarely just or mainly attributable to philosophical tensions. Distasteful as they may seem there are more proximal factors, often driven by financial spreadsheets and concerns over reputation. An analysis of the proximal and more local conditions is relevant if only because it is informative and because it is debatable whether there is always a causal role for the philosophy (philosophy can be read into a spreadsheet, but it need not have its origin).

In this volume, we are concerned to enhance our understanding of the relations between history and psychology and particularly of how history informs psychology. Many influential figures in the field of history of psychology have argued that psychology is intrinsically historical. As consequence history of psychology is a legitimate area of inquiry within psychology, and at the very least, historical considerations can inform the theoretical thinking of psychologists. These arguments have largely been expressed in intellectual terms, and our wish is not to denigrate them but to support them - after all, they are what drew both of us into the area. However, there is an equally noble tradition in historiography emphasising social relations and material conditions as vital components in the understanding of events: mainstream history. In this article we have shown how recent ideological shifts have affected British academic psychology. Managerialism and the resultant exercises in research assessment have often worked against the conceptual arguments for a more intimate relation between history and psychology. The result has been a marginalisation of history of psychology as an area of psychology and an increasing risk that the conceptual arguments for it will be swamped by other concerns. We want to emphasise that we consider this a theoretical interpretation.

We also wish to end on a positive note. We continue to believe that good history is persuasive and will be valued by open-minded colleagues. We believe that the history of psychology, though small and shrinking, can-and must - sustain col- 
laborative activities between scholars. Within the curriculum there is support for the idea that history of psychology should be taught, and we continue to believe that teaching history to psychology students can be enjoyable and fruitful and, dare we say it, can produce better psychologists.

\section{References}

Anderson, B. (2011). There is no such thing as attention. Frontiers in psychology, 2(246), 1-8.

Arnaud, S. (2015). On hysteria: The invention of a medical category between 1670 and 1820. Chicago: Chicago University Press.

Baritz, L. (1960). The servants of power: A history of the use of social science in American industry. Middletown, CT: Wesleyan University Press.

Barnes, B. (1977). Interests and the growth of knowledge. London: Routledge.

Barrett, L. F. (2006). Are emotions natural kinds? Perspectives on Psychological Science, 1(1), 28-58.

Bartlett, S. J. (1994). The psychology of faculty demoralization in the liberal arts: Burnout, acedia, and the disintegration of idealism. New Ideas in Psychology, 12(3), 277-289.

Bauman, Z. (2000). Liquid modernity. Malden, MA: Polity Press.

Bazerman, C. (1988). Shaping written knowledge: The genre and activity of the experimental article in science. Madison, WI: University of Wisconsin Press.

Bence, V., \& Oppenheim, C. (2005). The evolution of the UK's Research Assessment Exercise: publications, performance and perceptions. Journal of Educational Administration and History, $37(2), 137-155$.

Benneworth, P., \& Jongbloed, B. W. (2010). Who matters to universities? A stakeholder perspective on humanities, arts and social sciences valorisation. Higher Education, 59(5), 567-588.

Berche, B., Holovatch, Y., Kenna, R., \& Mryglod, O. (2015). Academic research groups: Evaluation of their quality and quality of their evaluation. arXiv:1511.08367.

Billig, M. (1989). Psychology, rhetoric, and cognition. History of the Human Sciences, 2(3), 289-307.

Billig, M. (1990). Rhetoric of social psychology. In I. Parker \& J. Shotter (Eds.), Deconstructing social psychology (pp. 47-60). London: Psychology Press.

Binkley, S. (2011a). Happiness, positive psychology and the program of neoliberal governmentality. Subjectivity, 4(4), 371-394.

Binkley, S. (2011b). Psychological life as enterprise: Social practice and the government of neoliberal interiority. History of the Human Sciences, 24(3), 83-102.

Bloor, D. (1976). Knowledge and social imagery. London: Routledge.

BPS. (2015, October). Standards for the accreditation of undergraduate, conversion and integrated Masters programmes in psychology. Leicester: British Psychological Society.

Brenninkmeijer, J. (2010). Taking care of one's brain: How manipulating the brain changes people's selves. History of the Human Sciences, 23(1), 107-126. doi:10.1177/0952695109352824.

Brinkmann, S. (2005). Human kinds and looping effects in psychology: Foucauldian and hermeneutic perspectives. Theory and Psychology, 15, 769-791.

Brockmeier, J. (2015). Beyond the archive: memory, narrative, and the autobiographical process. Oxford: Oxford University Press.

Brown, R., \& Carasso, H. (2013). Everything for sale? The marketisation of UK higher education. London: Routledge.

Brysbaert, M., \& Rastle, K. (2012). Historical and conceptual issues in psychology (2nd ed.). London: Pearson.

Bunn, G. C., Lovie, A. D., \& Richards, G. D. (Eds.). (2001). Psychology in Britain: Historical essays and personal reflections. Leicester: British Psychological Society. 
Callon, M., Rip, A., \& Law, J. (Eds.). (1986). Mapping the dynamics of science and technology. London: Palgrave Macmillan.

Christopher, J. C., \& Hickinbottom, S. (2008). Positive psychology, ethnocentrism and the disguised ideology of individualism. Theory and Psychology, 18(5), 563-589.

Collingwood, R. G. (1946). The idea of history. Oxford: Clarendon.

Collini, S. (2012). What are universities for? London: Penguin.

Cornejo, C. (2015). From fantasy to imagination: A cultural history and a moral for cultural psychology. Niels Bohr Lecture, Aalborg University.

Danziger, K. (1994). Does the history of psychology have a future? Theory and Psychology, 4(4), 467-484.

Danziger, K. (1997). Naming the mind: How psychology found its language. London: Sage.

Daston, L. (2000). Biographies of scientific objects. Chicago: University of Chicago Press.

Dean, M. (1999). Governmentality: Power and rule in modern society. London: Sage.

Dixon, T. (2003). From passions to emotions: The creation of a secular psychological category. Cambridge, UK: Cambridge University Press.

Foucault, M. (1973). The order of things: An archaeology of the human sciences. New York: Vintage Books.

Foucault, M. (1977). The archaeology of knowledge. London: Tavistock.

Foucault, M. (1988). Technologies of the self. In L. H. Martin et al. (Eds.), Technologies of the self (pp. 16-49). London: Tavistock.

Foucault, M. (1998). Philosophy and psychology. In J. D. Faubion (Ed.), Essential works of Foucault (Aesthetics, method, and epistemology, Vol. 2, pp. 249-259). New York: New Press.

Furnham, A., \& Lester, D. (2012). The development of a short measure of character strength. European Journal of Psychological Assessment, 28, 95-101.

Geekie, J., \& Read, J. (2009). Making sense of madness: Contesting the meaning of schizophrenia. London: Routledge.

Gergen, K. J. (1973). Social psychology as history. Journal of Personality and Social Psychology, 26(2), 309-320.

Giroux, H. A. (2002). Neoliberalism, corporate culture, and the promise of higher education: The university as a democratic public sphere. Harvard Educational Review, 72(4), 425-463.

Giroux, H. A. (2014). Neoliberalism's war on higher education. Chicago: Haymarket Books.

Goertzen, J. R. (2008). On the possibility of unification: The reality and nature of the crisis in psychology. Theory and Psychology, 18, 829-852.

Goodey, C. F. (2011). A conceptual history of intelligence and "intellectual disability": The shaping of psychology in early modern Europe. Farnham, UK: Ashgate.

Green, C. D. (1992). Of immortal mythological beasts: Operationism in psychology. Theory and Psychology, 2, 291-320.

Green, C. D., \& Feinerer, I. (2015). The evolution of The American Journal of Psychology 1, 1887-1903: A network investigation. American Journal of Psychology, 128(3), 387-401.

Green, C. D., Feinerer, I., \& Burman, J. T. (2013). Beyond the schools of psychology 1: a digital analysis of Psychological Review, 1894-1903. Journal of the History of the Behavioral Sciences, 49(2), 167-189.

Hacking, I. (1999). The social construction of what? Cambridge, MA: Harvard University Press.

Hacking, I. (2007). Kinds of people: Moving targets. Proceedings of the British Academy, 151, 285-318.

Hall, J., Pilgrim, D., \& Turpin, G. (Eds.). (2015). Clinical psychology in Britain: Historical perspectives. Leicester: British Psychological Society.

Harley, S. (2002). The impact of research selectivity on academic work and identity in UK Universities. Studies in Higher Education, 27(2), 187-205.

Herman, E. (1995). The romance of American psychology: Political culture in the age of experts. Berkeley, CA: University of California Press.

Hicks, D. (2012). Performance-based university research funding systems. Research Policy, 4(2), 251-261. 
Hug, S. E., Ochsner, M., \& Daniel, H.-D. (2014). A framework to explore and develop criteria for assessing research quality in the humanities. International Journal for Education Law and Policy, $10(1), 55-64$.

Hyde, A., Clarke, M., \& Drennan, J. (2012). The changing role of academics and the rise of managerialism. In B. M. Kehm \& U. Teichler (Eds.), The academic profession in Europe: New tasks and new challenges (The changing academic profession in international comparative perspective). Dordrecht: Springer.

Jones, D., \& Elcock, J. (2001). History and theories of psychology: A critical perspective. London: Arnold.

Khalidi, M. (2010). Interactive kinds. British Journal for the Philosophy of Science, 61, 335-360.

Krampen, G. (2016). Scientometric trend analyses of publications on the history of psychology: Is psychology becoming an unhistorical science? Scientometrics, 106, 1217-1238.

Lasalvia, A., Penta, E., Sartorius, N., \& Henderson, S. (2015). Should the label "schizophrenia" be abandoned? Schizophrenia Research, 162, 276-284.

Latour, B. (2005). Reassembling the social: An introduction to actor-network theory. Oxford: Oxford University Press.

Law, J., \& Hassard, J. (1999). Actor network theory and after. Oxford: Blackwell.

Leary, D. E. (1994). Metaphors in the history of psychology. Cambridge, UK: Cambridge University Press.

LeDoux, J. (2002). Synaptic self: How our brains become who we are. Journal of the Royal Society of Medicine, 95(7), 373-374.

Lee, F. S. (2007). The Research Assessment Exercise, the state and the dominance of mainstream economics in British universities. Cambridge Journal of Economics, 31(2), 309-325.

Lee, F. S., Pham, X., \& Gu, G. (2013). The UK Research Assessment Exercise and the narrowing of UK economics. Cambridge Journal of Economics, 37(4), 693-717.

Legrenzi, P., \& Umilta, C. (2011). Neuromania: On the limits of brain science. Oxford: Oxford University Press.

Lorenz, C. (2012). If you're so smart, why are you under surveillance? Universities, neoliberalism, and new public management. Critical Inquiry, 38, 599-629.

Martin, E. (2010). Self-making and the brain. Subjectivity, 3(4), 366-381.

Molesworth, M. (2010). The marketisation of higher education and the student as consumer. London: Routledge.

Moncrieff, J. (2006). Psychiatric drug promotion and the politics of neoliberalism. British Journal of Psychiatry, 188(4), 301-302.

Morawski, J. G. (1996). Principles of selves: The rhetoric of introductory textbooks in American psychology. In K. J. Gergen \& C. F. Graumann (Eds.), Historical dimensions of psychological discourse (pp. 145-162). Cambridge, UK: Cambridge University Press.

Niemiec, R. M. (2013). Mindfulness and character strengths: A practical guide to flourishing. Boston: Hogrefe.

Noë, A. (2009). Out of our heads: Why you are not your brain, and other lessons from the biology of consciousness. New York: Hill and Wang.

Owens, B. (2013). Judgement day. Nature, 502(7471), 288-290.

Palfreyman, D., \& Tapper, T. (2014). Reshaping the university: The rise of the regulated market in Higher Education. Oxford: Oxford University Press.

Parker, I. (2014). Managing neoliberalism and the strong state in higher education: Psychology today. Qualitative Research in Psychology, 11(3), 250-264.

Pumfrey, S., Rayson, P., \& Mariani, J. (2012). Experiments in 17th century English: Manual versus automatic conceptual history. Literary and Linguistic Computing, 27, 395-408.

Quality Assurance Agency. (2010). Subject benchmark statement: psychology 2007. Gloucester: Quality Assurance Agency.

Randall, W. L. (2007). From computer to compost: Rethinking our metaphors for memory. Theory and Psychology, 17(5), 611-633.

Richards, G. (1987). Of what is history of psychology a history? British Journal for the History of Science, 20(2), 201-211. 
Richards, G. (1989). On psychological language and the physiomorphic basis of human nature. London: Routledge.

Richards, G. (2002). The psychology of psychology: A historically grounded sketch. Theory and Psychology, 12(1), 7-36.

Richards, G. (2009). Putting psychology in its place: Critical historical perspectives (3rd ed.). London: Routledge.

Roediger, H. L. (2008). Why the laws of memory vanished. Annual Review of Psychology, 59, $225-254$.

Rogers, T. B. (1989). Operationism in psychology: A discussion of the contextual antecedents and an historical interpretation of its longevity. Journal of the History of the Behavioral Sciences, $25,139-153$.

Rose, N. (1985). The psychological complex. London: Routledge.

Rose, N. (1989). Governing the soul: The shaping of the private self. London: Routledge.

Rose, N. (1996). Inventing ourselves: Psychology, power and personhood. Cambridge, UK: Cambridge University Press.

Rose, N. (2003). Neurochemical selves. Society, November/December, 46-59.

Rose, N., \& Abi-Rachid, J. M. (2013). Neuro: The new brain sciences and the management of the mind. Princeton, NJ: Princeton University Press.

Rose, H., \& Rose, S. (1970). Science and society. Harmondsworth, UK: Penguin.

Satel, S., \& Lilienfeld, S. O. (2013). Brainwashed: The seductive appeal of mindless neuroscience. New York: Basic Books.

Shorter, E. (2013). How everyone became depressed: The rise and fall of the nervous breakdown. Oxford: Oxford University Press.

Smith, R. (2005). The history of psychological categories. Studies in History and Philosophy of Biological and Biomedical Sciences, 36, 55-94.

Smith, R. (2007). Being human: Historical knowledge and the creation of human nature. Manchester, UK: Manchester University Press.

Smith, R. (2013). Between mind and nature: A history of psychology. London: Reaktion Books.

Smyth, M. M. (2001). Fact making in psychology: The voice of the introductory textbook. Theory and Psychology, 11(5), 609-636.

Somerville, S. B. (2000). Queering the color line: Race and the invention of homosexuality in American culture. Durham, NC: Duke University Press.

Susman, W. (1984). Personality and the making of twentieth-century culture. In Culture as history: The transformation of American society in the twentieth century (pp. 271-285). New York: Pantheon Books.

Sussman, R. W. (2014). The myth of race: The troubling persistence of an unscientific idea. Cambridge, MA: Harvard University Press.

Tallis, R. (2011). Aping mankind: Neuromania, Darwinitis and the misrepresentation of humanity. Durham, UK: Acumen.

Tate, C., \& Audette, D. (2001). Theory and research on "race" as a natural kind variable in psychology. Theory and Psychology, 11, 495-520.

Teigen, K. H. (1994). Yerkes-Dodson: A law for all seasons. Theory and Psychology, 4(4), 525-547.

Teigen, K. H. (2002). One hundred years of laws in psychology. American Journal of Psychology, 15(1), 103-118.

Thomson, M. (2006). Psychological subjects: Identity, culture, and health in twentieth-century Britain. Oxford: Oxford University Press.

Timimi, S. (2005). Naughty boys: Anti-social behaviour, ADHD and the role of culture. Basingstoke, UK: Palgrave Macmillan.

Tsou, J. Y. (2007). Hacking on the looping effects of psychiatric classifications: What is an interactive and indifferent kind? International Studies in the Philosophy of Science, 21(3), 329-344.

Tyson, P. J., Jones, D., \& Elcock, J. (2011). Psychology in social context: Issues and debates. London: John Wiley. 